\title{
Economics of ecosystem restoration: using derived demand to promote sustainable ecosystems
}

\author{
D. B. Rideout, D. Rossi \& N. Kernohan \\ WestFire Research Center, Department of Forest and Rangeland \\ Stewardship, Colorado State University, USA
}

\begin{abstract}
Land managers face a complex set of choices when developing restoration and management strategies to promote resilient landscapes. Restoring landscapes is costly; making full restoration beyond the means of most land management agencies. This necessitates difficult choices and a careful consideration of which areas of the landscapes to restore and how intensively they should be restored to achieve the greatest net benefit. We define the problem in the context of derived demand where optimal restoration is derived from the value to the ecosystem or landscape. The derived demand framework enables us to closely integrate economics with ecological principles of restoration and resiliency to arrive at cost effective solutions. We develop the economic framework for identifying and selecting the most advantageous sites to restore given a fixed restoration budget. This framework informs and guides budget allocations across market and nonmarket goods and services to optimally restore the natural capital. The theoretical development is demonstrated with a case study showing the value added achieved from introducing a restoration management effort (fuel treatment) at Sequoia and King's Canyon National Park in the United States.

Keywords: restoration, economics, natural capital, environmental capital, return on investment.
\end{abstract}

\section{Introduction}

Public land management agencies embraced ecosystem management in the 1990s, resulting in a broad set of complex ecosystem values to consider. With no pragmatically viable economic methodology for relating changes in the value of ecosystem services to management alternatives, the "Committee of Scientists" [1] 
proposed to use and measure a particular ecosystem's departure from a baseline or reference condition as a foundational concept. Management effort involving restoration would be required to bring the ecosystem back to the "baseline condition". Hardy et al. [2] and Hann and Bunnell [3] introduced "condition class" (CC) to measure the departure of the current ecosystem condition from a reference condition. For managerial purposes, CCs are typically constructed to define three to five distinct conditions. Customarily, CC 1 meets the most desirable ecological standard ("excellent condition"), while higher numbered CCs are increasingly less desirable. Further, the classification scheme is often specific to each eco-type or natural community.

The overall purpose of assigning CCs across a landscape is to identify areas that would have a high priority for restoration treatments. In a specific managerial example for managing National Forest in Florida, [4] five CCs were identified to provide the foundation for: 1. prioritizing treatments, 2 . for balancing restoration with maintenance treatments (where maintenance treatments are used to keep an ecosystem in a desirable condition) and, 3. to increase management efficiency. While this is a specific example, it is representative of land management decisionmaking processes that depend solely on biophysical metrics. While physical metrics are crucial to meeting managerial objectives, they omit the economic content essential to guide cost-effective allocations of scarce resources. Implicitly assuming that lands in poor condition such as CC 5, would be restored to a more desirable condition, fails to address the important reality that restoration choices depend as much on values and costs as they do on CC. Assume two areas where one is predominantly ponderosa pine and the other is primarily sequoia and both are classified as CC 5. If funds are available to only restore one of them, then CC provides no guidance as to how to allocate management resources.

In its most basic form, ecological restoration represents re-investment in the natural capital that provides a flow of benefits (i.e. nature's services over time). The question that should guide the investment process is, "Where and how can investments be made to provide the greatest return in a world of scarce resources reflected by limited budgets?" This question and the stated purposes of restoration (above) cannot be adequately addressed without integrating sound economic analysis with the biophysical information.

\section{Integration of economics and ecological restoration}

A sound economic approach to investing in restoration (natural capital) requires information on the physical condition of the capital asset as well as the cost and value of restoration. Valuation often proves to be the most problematic information to reliably obtain. Many of the benefits of restoration are characterized as non-market services where pricing information is not readily available. Hence, economists have often relied on stated preference approaches to obtain such values. In stated preference approaches, questions are asked of a set of potential respondents, under controlled conditions, to generate value estimates. Many traditional approaches to stated preference have been criticized as being unreliable or as too costly to obtain. For example, Gregory and Slovic [5] indicate the 
difficulties of using traditional stated preference methods to determine the value of environmental goods and services with multi-dimensional characteristics. When an ecosystem experiences a broad range of deviations from its desired state across a spatial scale, a multi-attribute elicitation of service trade-offs are needed to determine if marginal adjustments to ecosystem structure can provide social value added. Schultz et al. [6] argue that stated preference methods must be coupled with accepted indicators of ecological condition to determine the marginal value of an additional unit of improvement in that condition.

A key issue with the use of stated preference approaches is the recognition that the problem requires answering the question concerning the value of managerial action that will improve a complex ecosystem. The value of the managerial action and the condition of a complex ecosystem are both beyond the understanding of the general public making traditional stated preference approaches of questionable relevance. Instead, posing the question to knowledgeable officials tasked with the daily management of the ecosystem is more likely to produce an informed response. This also requires recognizing that the demand (value) for managerial action is derived from the value of the ecosystem. With this consideration a derived demand approach is addressed.

The MARS stated preference valuation method was designed to addresses the above concerns in a restoration context (Rideout et al., [7]). Through a structured elicitation of preferences, decision makers provide estimates of marginal restoration value. A familiar environmental asset is defined as the numeraire asset to provide a reference to enhance the ability of officials to make comparisons of relative value. It also establishes a non-monetized currency that facilitates the elicitation process. Marginal rates of substitution $(M R S)$ (the value of restoring one natural asset class relative to another asset class) are obtained for all relevant assets on the study site. Classic utility theory provides the foundation such that we can express utility (benefit) as a function of the set of the natural assets: $U\left(A_{1}, A_{2}, \ldots A_{n}\right)$. Each asset could exist on any hectare over the planning unit. Here, $U\left(A_{1}\right)$ denotes the benefit of restoring one hectare of asset 1 . The rates of substitution between assets are defined by the slope of the utility function with respect to other assets at the forest's "baseline" endowment of human, cultural, and natural assets that may be improved with restoration effort.

$$
M R S_{n}=-\frac{\partial U / \partial A_{1}}{\partial U / \partial A_{n}}
$$

The rates of substitution defined by (1) denote the marginal value of treating a hectare of any particular asset. The value added $(V A)$ from treating any hectare $i$ with asset $n$ is defined by (1). This is performed pragmatically by using the principles and techniques of the "MARS" valuation system discussed in the case study below.

For a hectare (or cell) containing $N$ restorable assets, we sum the improvement value across each asset as shown in (2). Here, we use the example of environmental capital that depreciates in value naturally with time $(T)$. This implies that the value added from a current restoration effort depends upon the amount of time since the previous restoration effort assuming the previous restoration was fully effective. This example could be modified to reflect asset 
degradation for other reasons such as industrial activity or recreational use. With this example, the value added $(V A)$ from restoration is dependent on the time since last treatment $(T)$.

$$
V A_{i}=\sum_{n=1}^{N} M R S_{n}\left(T_{i}\right)
$$

For a depreciating asset with respect to time $\frac{\partial M R S_{n}}{\partial T}<0$, and this derivative denotes the natural rate of depreciation. Such depreciation can occur in natural systems where man has excluded or limited a natural process such as fire. A natural fire-dependent system will typically decay with time unless treated, for example by a restorative fuel treatment as in the case study discussed below. The value added from the treatment would depend upon the particular asset and the time since it was last treated, $V A(T)$. Most treatment schemes involve natural assets, For example, if a hectare of land were treated to improve song-bird habitat and long-leaf pine, then the value of the improvement is additive across those two assets $(n)$ as shown in (2).

The potential to add value across the entire landscape is shown in (3) where value added is summed across all cells (hectares) $I^{0}$.

$$
T V A=\sum_{1}^{I^{0}} V A_{i}
$$

To maximize the net benefit of a fixed restoration budget " $B$ " " across many natural assets and hectares, we select the hectares on the landscape (I) that provide the greatest net restoration value added without exceeding the budget. This can be expressed as:

$$
\left.M A X=T V A(I)+\lambda\left[B^{o}-C(I)\right)\right]
$$

where the cost of restoration is denoted by $\mathrm{C}(\mathrm{I})$. The first-order conditions for selecting hectares to treat is denoted as:

$$
\frac{d T V A}{d I}=\lambda\left(\frac{d C}{d I}\right)
$$

Equation (5) states that the hectares selected for treatment generate a benefit greater than or equal to the budget-constrained $(\lambda)$ marginal cost of treatment. Lambda denotes the marginal value of increasing (decreasing) the restoration budget by one unit of currency in which $B^{o}$ is expressed. A more pragmatic and equivalent interpretation is to treat cells from highest to lowest net value added until the budget is expended.

\section{Restoring the desired landscape condition}

To demonstrate the application of the above economic concepts into the decisionmaking process we provide an example using a study site where restoration management planning is critically engaged with a spectrum of human and ecosystem values. We quantify and show the effects of alternative planning strategies on the improvement of the desired management condition. While the restoration management effort used here is fuel treatment a similar approach could 
be used with an alternate restoration management effort (non-fire) to support other specific restoration management analysis.

\subsection{Study site - Sequoia and Kings Canyon National Park}

Sequoia and Kings Canyon National Parks (SKNP) is located in the western Sierra Nevada mountain range in California and consists of about 360 thousand hectares. The park contains; sequoia groves, vast tracts of montane forest, subalpine woodlands, oak woodlands and chaparral. Years of fire exclusion have degraded the natural condition such that it can benefit from fuel treatment restoration efforts [8].

\subsection{Assessing the current condition}

We begin by using equation (3) to assess the baseline condition of the study site. The strategic spatial management and planning system STARFire [10] facilitates these computations. Consistent with the restoration literature, the baseline assessment represents the current condition of the landscape relative to a desired (fire) management condition. The baseline assessment requires three core data sets. The first reflects the spatial fire behaviour characteristics of the study area and the second is used to estimate the value change of the restoration effort (fire effects) and associated treatment costs. The third considers fire history information to inform time since last fire and estimates of ignition density which in turn, inform burn probability.

Fire behaviour was estimated using the public domain software FlamMap5 from FIRE.org (a fire behaviour analysis program that computes potential fire behaviour characteristics over an entire landscape using constant weather and fuel moisture conditions). The resulting spread rate $(\mathrm{m} / \mathrm{min})$, fire intensity $\left(\mathrm{BTU} / \mathrm{ft}^{2}\right)$, maximum spread direction (degrees), and flame length (m) calculations were provided to STARFire. The data used to run FlamMap were downloaded from LANDFIRE (an interagency vegetation, fire and fuel characteristics mapping program).

The MARS (Marginal Attribute Rate of Substitution) [7] valuation system was used to estimate the relative marginal value $(R M V)$ of fire effects for restoration efforts. Using a structured elicitation process, SKNP resource professionals identified the resources (human and natural) whose values were positively or negatively affected by fire. Next, the fire-induced value changes of resources at different intensities/severities were explicitly quantified. The return interval for cover types whose $R M V$ is sensitive to time since last fire/treatment was established. Resources assessed included: protection of property, cultural resources (Giant Sequoias) and forest cover species (including Foxtail Pine, Ponderosa Pine, Sequoia Groves, Red Fir, Lodgepole Pine, Foothill Chaparral and Montane Chaparral). Figure 1 shows the spatial arrangement of these resources.

Fuel treatment cost can vary depending on scale, cover type, ecosystem condition (maintenance vs. restoration) and broad fuel type (grass like, tree like and shrub like). Treatment costs reflecting these combinations were obtained from SKNP and supplied to the analysis. 


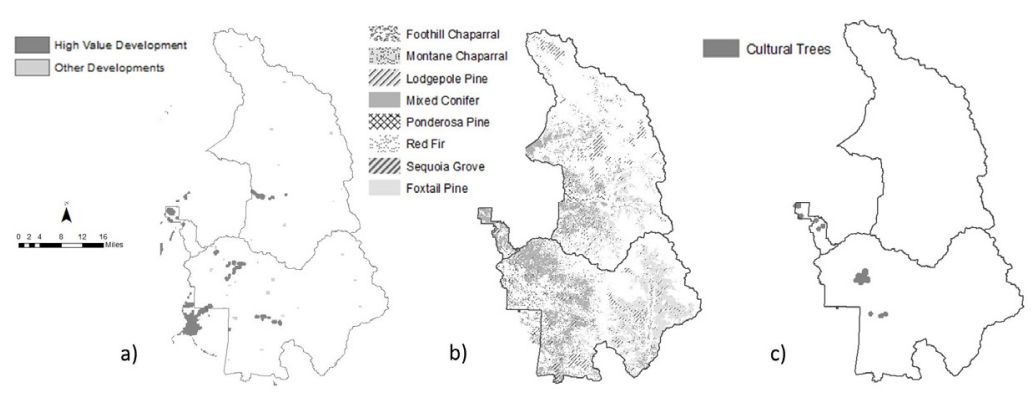

Figure 1: Spatial location of selected fire management resources. (a) shows human development, (b) vegetation cover types, (c) shows cultural resources.

Spatial layers representing fire history, ignition locations and fire perimeters were obtained from SKNP and were used to supply estimates of ignition density and support burn probability calculations. A 'time since last fire' raster was generated from the fire perimeter polygons and used to support the MARS evaluation.

With these three core datasets in place, STARFire analyzed the landscape to identify the potential to add value through fuel treatments. Fuel treatments can add value by restoring the ecosystem (fully or partially) to a more desired condition, but can also add value by improving burn conditions (lower intensity) or reducing the burn probability in locations that have the potential to harm life and/or property. This potential is recorded for each raster cell on the landscape.

\subsection{Well-informed decision making}

By applying equation (5) we were able to address the question from section 1 above: "Where and how can investments be made to provide the greatest return?" Using the potential valued added for each raster cell, cost was introduced to identify the raster cells that produce the highest return on investment (ROI). By expanding the budget, the number of treatable cells increased and a set of wellinformed management alternatives were generated as in Figure 2 below.

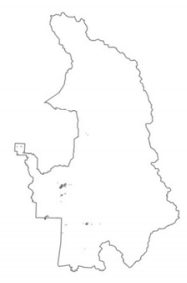

Current

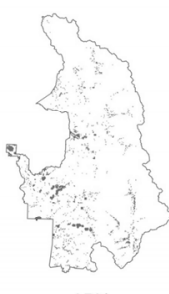

$15 \%$

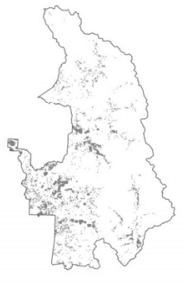

$25 \%$
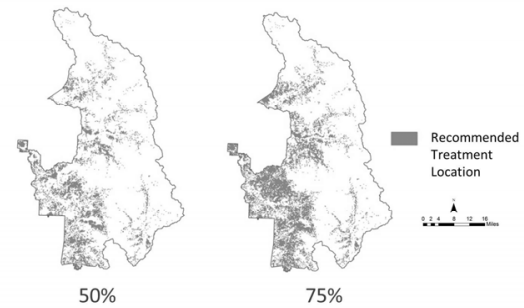

Figure 2: Each panel shows recommended treatment alternatives arrived at by maximizing ROI. Moving right across the panels shows increased treatment budgets. 


\subsection{Quantifying the management effort on the landscape}

To simulate the effects of the fuel treatment management effort, the three core data sets for each management alternative were updated to reflect the physical effectiveness of the treatment. The fire history data set was updated to reflect the treatment perimeters (the resulting changes to fire intensity and time since last fire influences the post treatment $R M V^{\prime} S$ used in STARFire). Post treatment fire behavior data was generated in FlamMap5 by updating the fire modeling landscape. STARFire was used to reprocess the landscape and define the post treatment condition.

The difference between the expected value of the pre and post treatment landscapes approximates the value added by a particular fuel treatment application on the landscape. This was calculated for each management alternative and is expressed as a net benefit (return-cost).

\section{Results}

Results of the case study analysis show that increases in the investment or budget level, when applied to the sites producing the greatest return on investment, generated increasing valued added at a diminishing rate as shown in Figure 3. Note that if the currency used is the same for cost and for return, the shape of the curve will be unaffected. From observing Figure 3, a budget allocation located on the $\mathrm{x}$ axis can be demonstrated to produce the return shown on the y-axis so long as the treatment is selected in a manner that produces the greatest return on investment.

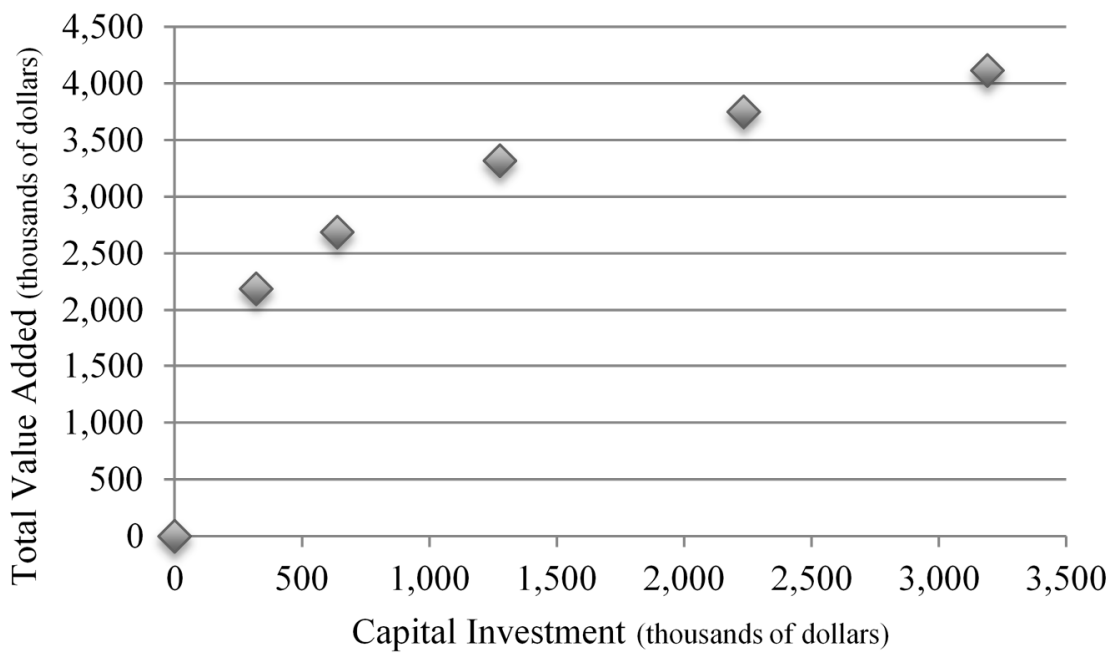

Figure 3: Total value added (thousands of dollars) over capital investment (thousands of dollars) showing diminishing returns. 


\section{Conclusions}

One of the global challenges facing many natural landscapes is the restoration of natural capital to a desired condition. Scarce resources reflected in fixed budgets results in complex land management choices including; the prioritization of restoration treatments, choosing between new restoration efforts and the maintenance of existing treatments, and the ability to increase management efficiency. In a first-level analysis, biophysical information is inadequate to guide or resolve choices. Likewise, economically naive systems that search for spatial patterns while applying scoring systems are similarly handicapped. However, when biophysical information is integrated with marginal values and costs wellinformed cost-effective decisions can be achieved. When the biophysical information is properly integrated with marginal analysis; including marginal values and costs, land managers can select the treatment locations producing the greatest return on investment for their restoration effort, as shown in the case study, they can optimally allocate the limited budget to produce the greatest program benefit. Two key considerations bridge the integration: 1. recognizing that the value of restoration effort is derived from the value added to the landscape through treatment and 2. using a marginal value system such as MARS. In a second-level analysis, a sound demonstration of cost-effective decision-making and resource allocation promotes compelling arguments for enhancing restoration budget allocations.

\section{References}

[1] Committee of Scientists, Sustaining the People's Lands: Recommendations for Stewardship of the National Forests and Grasslands in the Next Century, a report to the Secretary of Agriculture and to the Chief of the Forest Service. Washington DC: US Department of Agriculture, pp. 34-35, March $15,1999$.

[2] Hardy, C.C., Schmidt, K.M., Menakis, J.M., and Samson N.R., Spatial data for national fire planning and fuel management. International Journal of Wildland Fire. 10, pp. 353-372, 2001.

[3] Hann, W.J. and Bunnell D.L., Fire and land management planning and implementation across multiple landscapes. International Journal of Wildland Fire. 2001.

[4] Drake, J and Medley P., Ecological Condition Model for the National Forests in Florida. USDA Forest Service, Tallahassee, FL. p. 21.

[5] Gregory, R and Slovic P., A constructive approach to environmental valuation. Ecological Economics, 21, pp. 175-181, 1997.

[6] Schultz, E. T., Johnston, R. J., Segerson, K., \& Besedin, E. Y., Integrating Ecology and Economics for Restoration: Using Ecological Indicators in Valuation of Ecosystem Services. Restoration Ecology, 20(3), pp. 304-310, 2012. 
[7] Rideout, D.B., Ziesler, P.S., Kling, R. Loomis, J.B. \& Botti, S.J., Estimating rates of substitution for protecting values at risk for initial attack planning and budgeting. Forest Policy and Economics, 10, pp. 205-219, 2008

[8] Caprio, A.C., Graber, D.M., Returning fire to the mountains: Can we successfully restore the ecological role of pre-Euro American fire regimes to the Sierra Nevada? Wilderness science in a time of change conference, Proceedings RMRS-P-15. Department of Agriculture, Forest Service, Rocky Mountain Research Station, ed. D.N. Cole, S.F. McCool, J. O’Loughlin: Missoula, MT, US, 3, pp. 233-241, 2000.

[9] Fire and Fuels Management Plan 2011 Annual Update; Sequoia \& Kings Canyon National Parks, National Park Service, US. Department of the Interior, www.nps.gov/seki/naturescience/upload/2011-FFMP-final_ reduce-file-size.pdf.

[10] Manley, J., Rideout, D.B., Wei, Y., Botti, S.J., STARFire: Decision support for strategic integration of wildland fuels and unplanned ignitions. Proceedings of the 3rd Fire Behavior and Fuels Conference. International Association of Wildland Fire: Spokane, WA, 2011. 